\title{
Experimentality, surplus data and the politics of debilitation in borderzones
}

\author{
Claudia Aradau, King's College London
}

This is a pre-publication copy. The final version is available at https://www.tandfonline.com/doi/full/10.1080/14650045.2020.1853103?src=

Aradau, C. (2020) Experimentality, Surplus Data and the Politics of Debilitation in Borderzones. Geopolitics:1-21. doi: 10.1080/14650045.2020.1853103.

\begin{abstract}
The use of digital devices and the collection of digital data have become pervasive in borderzones. Whether deployed by state or non-state actors, digital devices are rolled out despite intense criticism and controversy. In this article, I propose to approach these interventions through the prism of experimentality. Experimentality was initially formulated in the anthropological literature on the globalisation of clinical trials and, more recently, revisited in feminist science and technology studies. Drawing on this work, I argue that experimentality has become a rationality of governing in borderzones, which renders social relations continuously decomposable and recomposable by inserting mundane (digital) devices into the world. The introduction of various digital devices in Greece since 2015, starting with Skype for the pre-registration of asylum seekers, helps shed light on a particular form of governing through experiments without protocol. This form of experimentality has specific political effects for migrants' lives. Firstly, experimentality builds upon and intensifies neoliberalism by rearranging rather than redressing precarity. In so doing, experimentality through digital devices produces debilitation rather than better connectivity or access to asylum. Secondly, migrants become not only subjects of surveillance, but subjects of extraction of 'surplus data' which entangles their lives into the circuits of digital platforms.
\end{abstract}

\section{Introduction}

In 2016, Rania Ali started a petition on change.org entitled 'Skype is no solution - we need face-to-face services for refugees in Greece'. The petition was addressed to the EU Commissioner for Migration, Home Affairs and Citizenship, Greek Ministry of Interior and the Head of the Greek Asylum Service. In the petition, Rania outlines the effects that Skype technologies have for asylum seekers:

My husband and I want to apply for relocation to another country in Europe to escape from this situation. I have tried to call the Skype Asylum service for $\mathbf{2 0}$ days with no 
answer. For us refugees here in Greece, our lives are reduced to a routine of sleeping and waiting. Waiting in line for food, to go to the bathroom, to charge our phones, and waiting on hold for a Skype call that is never picked up. Our lives are stuck in limbo.

\section{Waiting on-hold is frustrating, but when your life depends on the call?}

For people living in camps with limited access to electricity, smart phones, computers, or internet, this is a cruel and senseless procedure. If it is our right to claim Asylum, then why are there such impossible barriers to do so? (Ali 2016b emphasis in original)

The petition received 212,783 signatures, but no official response. In July 2016 , Rania posted a message to the petition followers explaining that she and her husband had had recourse to fake IDs and had made their way to Austria (Ali 2016a). At the time, Skype still remained the only option for asylum seekers on the mainland in Greece to have access to the asylum process or relocation. ${ }^{1}$

Skype is only one of the many technologies deployed in Greece to govern the lives of refugees through pilots and projects funded by the European Commission as well as other state and non-state actors. From a pilot project to introduce a 'floating wall' in the Aegean sea to stop refugees crossing from Turkey (Digidiki and Bhabha 2020) and the deployment of surveillance drones in the Mediterranean (Euro-Mediterranean Human Rights Monitor 2020) to humanitarian FabLabs equipped with 3D-printing for refugees in Greece (Terre des hommes n.d.) and the infamous iBorderCtrl lie detector (Gallagher and Jona 2019), technologies have proliferated in border governance. Greece is a particularly relevant case as its borderzones have been intense sites of technologisation and digitisation since the 'refugee crisis' of 2015. Yet, the proliferation of (digital) devices is neither new nor unique to Greek borderzones. ${ }^{2}$ Even as high-tech developments such as the EU's extension of biometric data collection, database interoperability and data sharing with border and other authorities in non-EU countries (Amnesty International 2019; Statewatch and PICUM 2019) have attracted most public attention, the datafication of borders means that mundane digital devices are also increasingly deployed in borderzones.

This article proposes to attend to the experimental rationalities that shape these technological deployments. While much of the public and academic attention has focused on the introduction of 'high-tech' developments, from building interoperability to Al, I attend to the more mundane data collection devices such as VoIP technologies and mobile apps. ${ }^{3}$ The introduction of mundane digital devices such as Whatsapp, Skype, Mastercard, or apps does not require a laboratory or randomised custom trials we usually associate with experiments.

In order to account for the proliferation of devices in governing borders and explore their political effects, I introduce and develop the concept of experimentality. Experimentality was formulated by the anthropologist Adriana Petryna (2009) in her work on the globalisation of clinical trials and extended to humanitarian HIV programmes by Vinh-Kim Nguyen (2009). More recently, feminist Science and Technology Studies (STS) scholar Michelle Murphy has recast experimentality as a distributed assemblage that creates 'a milieu amenable to 
capitalism's desire for changing and changeable surroundings' (Murphy 2017, 81). Drawing on conceptualisations of experimentality in anthropology and STS, I interrogate the effects of experimentality upon the subjectivity of migrants in borderzones. ${ }^{4}$

To trace the distinctiveness of experimentality, I explore the controversies around the introduction of Skype for the pre-registration of asylum claims in Greece. The so-called 'Skype procedure' had been introduced in Greece in 2015, following criticism of the difficulties of access to the asylum procedures. Asylum seekers on the mainland are required to call the Asylum Service at particular times of the day in order to reach an interpreter for specific languages and pre-register their claim. As Rania's petition indicates, the Skype procedure was fraught with problems. Yet, despite wide-ranging criticisms by refugees, NGOs and international organisations, Skype was not replaced, but it was supplemented with other digital devices. The use of Skype was extended to more languages -18 at the time of writing - and it was supplemented by an app developed at the Harokopio University of Athens in collaboration with the Greek Asylum Service as part of a project funded from the EU Asylum, Migration and Integration Fund (AMIF) (Makris et al. 2017).

To develop these arguments about experimentality, the paper proceeds in three steps. Firstly, I explore the different understandings of experiment and experimentality as developed in international relations (IR), anthropology and STS. While in IR the notion of 'experiment' has been used in critical work on borders and humanitarianism, it has often been deployed either metaphorically or in the sense of hypothesis- or theory-testing. I argue that experimentality in borderzones inserts technical devices into reality with the aim of (re)composing social relations. How do these practices of experimentality affect the lives of migrants and refugees? In the next two sections, I trace the sinuous lines of controversies and their public production of inscriptions in the form of documents, reports, legal judgements, blogs, tweets, schedules, privacy policies and regulations. The second section investigates how experimentality recomposes social relations between state and refugees by rearranging relations of precarity under neoliberalism. Thirdly, I analyse how experimentality can shed light on the enrolment of refugees within digital platforms as subjects of data extraction.

\section{Governing borders: bricolage, improvisation, experimentality}

Critical work in border and migration studies has highlighted the pervasiveness of quick 'fixes', bricolage or improvisation in border practices. As Tobias Eule et al have put it, migration regimes are akin to Lévi-Strauss's concept of 'bricolage' rather than any 'masterplan' (Eule, Loher, and Wyss 2018, 2721). The 'masterplan' is thus the opposite of concepts and practices of improvisation or bricolage. Governing practices always have an improvisational quality, unexpected effects and messy recombinations of elements. William Walters has emphasised that 'technologies of control are cobbled together somewhat adventitiously' (Walters 2015). Giuseppe Sciortino's widely cited description of migration regimes encompasses these different elements through the 'mix of rather implicit conceptual frames, generations of turf wars among bureaucracies and waves after waves of "quick fix" to emergencies [... and] 
allows for gaps, ambiguities and outright strains: the life of a regime is a result of continuous repair work through practices' (Sciortino 2004, 32). Sciortino's migration regimes echo Paul Rabinow's definition of assemblages as 'a distinctive type of experimental matrix of heterogeneous elements, techniques and concepts' $(2003,56)$. In that sense, improvisation, recombination and heterogeneity are not pathologies of governmental assemblages, but their conditions of possibility. As Bourne, Johnson and Lisle $(2015,316)$ have aptly put it, 'surprises, detours, mistakes, and misfires [...] underscore contemporary bordering practices'.

Shedding light on the unexpected, ambiguous and even chaotic effects of improvisation and bricolage helps offer an implicit or explicit critique of these governing and bordering - practices. In the case of Greece, Katerina Rozakou (2017) has shown that the improvised aspects of dealing with migration through nonrecording and 'irregular' bureaucratic practices are not failures but the means of statecraft. In her analysis of the ambiguities of the 'pink card' which used to be allocated to asylum seekers in Greece, anthropologist Heath Cabot has also pointed out that ' $[t]$ hings themselves, with their complex and indissoluble materialities, are central participants in the indeterminate art of governance' $(2014,81)$.

This understanding of bricolage, improvisation and indeterminacy is often supplemented by the explicit metaphors of experiments and laboratories (for example Bialasiewicz 2012; Campesi 2018; Tazzioli 2019). European borders appear as 'a remarkable site of unprecedented experimentation and improvisation, a transnational and intercontinental laboratory for the regimentation and subordination of human powers and freedoms in relation to the space of the plant' (De Genova 2017, 24). Here improvisation, experiments and laboratories mobilise an understanding of governing practices as contingent and therefore always characterised by tinkering, misfires and improvisation. This understanding echoes sociological literature which has seen social life as experimental, but it risks ignoring how experiments introduce 'something new in social life' (Marres and Stark 2020, 428).

A second approach has connected experiments (within or outside a laboratory) to the STS literature. ${ }^{5}$ Experiments are not metaphors, but analytical tools that mobilise the history of 'experimental life' since the $17^{\text {th }}$ century, and the entanglements between modern science and social order (Shapin and Schaffer 1985). Recent critical work on humanitarianism has started to develop such an analytical approach to experiments in humanitarian governance. In particular, Katja Lindskov Jacobsen has offered a powerful analysis of the transformation of humanitarian experimentation through digital technologies such as biometric data collection (Katja Lindskov Jacobsen 2015a; Katja Lindskov Jacobsen 2015b). She situates experiments within a dual history of scientific and medical experimentation, which connect experiments and colonialism (Katja Lindskov Jacobsen 2015b). 'Testing' objects is transposed onto 'testing' subjects, with all the implications about exposing vulnerable bodies to risks of intervention and harm.

Rather than understanding the social as experimental, experiments are here particular scientific practices, often conducted in laboratories. The politics of experiments is the politics 
of science and technology, with its protocols, ethics and demands for objectivity. Even when STS scholars have criticised these protocols, they have shown that experiments rely on 'technical, literary, and social practices whereby experimental matters of fact were to be generated, validated, and formed into bases for consensus' (Shapin and Schaffer 1985). This is the deconstructive reading of 'experimental life' that Steven Shapin and Simon Shaffer have done in their seminal Leviathan and the Air-Pump (1985). STS work on experiments has also emphasised the gendered, racialised and class aspects of experimental protocols. Experiments required present or distant 'gentleman-witnesses' and relied upon data collection through networks of merchants across colonial empires (e.g., Sargent 2004).

These two approaches frame experiments as largely opposites. In a governmentality approach, all bordering practices have an experimental element. In an STS approach, experiments and laboratories have a more specific meaning emerging from the history of experiments in modern science. The notion of experimentality as coined in the anthropological literature on clinical and pharmaceutical experiments can be seen as an attempt to bridge these differences between scientific experiments and practices of governing. For the anthropologist Adriana Petryna (2009), experimentality captures an emerging mode of governance built around the mobility of clinical trials. In her work in Brazil and Poland, Petryna was particularly interested in how variations in experimental protocols had different ethical implications around the world, how they enabled a 'paradigm of expected failure' and lack of accountability (see also Nguyen 2009, 213). Yet, experimentality remains tied to the understanding of experiments used in the medical and pharmaceutical industries. These are characterised by protocols, which include ethical standards, informed consent and oversight.

Drawing on the STS literature on experiment, I propose to extend the conceptualisation of experimentality along three lines.

Firstly, while not all practices are experimental, experiments have increasingly taken more heterogeneous forms. In the case of mundane (digital) devices, there is no experiment specifically located the laboratory space-time, but pilots, projects, and trials. What differentiates these from the experiments Petryna analyses is not only that they are deployed outside the laboratory or the clinic, but that they often work without protocol. Protocols are documents, scripts that record the design, procedures and ethical guidance for research more broadly. In a special issue dedicated to experimentation in South Asia, Fouzieyha Towghi and Kalindi Vora (2014) have also drawn attention to the implications of doing experiments without representing them as such. For them, experimental interventions 'produce different populations as experimental bodies without explicitly marking the subjects as objects of experimentation or the space of the experiment as a laboratory' (Towghi and Vora 2014, 4). This means that populations enrolled as objects of experimentation do not have the rights to information and accountability associated with spaces such as the laboratory, thus further 'veiling the exploitative and expropriative aspects of experiments' (Towghi and Vora 2014, 5). 
Secondly, in the STS literature, experiments are understood as interventions, following lan Hacking's distinction between representing and intervening (1983). These interventions depend on material devices or apparatuses that produce new phenomena. For instance, the microscope makes experiments possible, as it shifts practices from 'peering' to 'interfering' (Hacking 1983). Yet, there has been less attention to the technologies and devices - particularly mundane digital devices - of experimental interventions in borderzones and how they make something different happen.

Thirdly, the proliferation of experiments outside laboratories needs to be understood in connection with developments under neoliberalism. Tracing experimentality to development interventions in 1970s Bangladesh, Murphy argues that a new form of experimentality emerged where 'the state was dysfunctional or where large social-technical infrastructures of industrialization and modernization did not reach' $(2017,79)$. While not all experiments rely on small-scale trials and produce interventions where state resources and infrastructures are lacking, there is a distinctive form of experimentality that emerges in conditions of neoliberalism, and which relies on pilot projects, trials and a cycle of funding applications and donor reports to fund more experiments. Experimentality harnesses neoliberal logics as well as 'responsibilized citizens who appropriately self-invest in a context of macroeconomic vicissitudes and needs that make all of these investments into practices of speculation' (Brown 2015, 84). Experimentality and neoliberalism share an orientation towards speculative futures.

The remainder of the article explores experimentality as a mode of governing in borderzones. Experimentality captures how social and political problems are rendered governable through experiments. While experimentality encompasses varied types of governing through experiments, I am particularly interested here in experiments without protocol. Not everything is an experiment and not all experiments are devised according to scientific or laboratory protocols. In focusing on experiments without protocol, I draw attention to specific political effects emerging through the entanglements of experimentality, subjectivity, neoliberalism and data. The introduction of Skype in the asylum process in Greece or the creation of an Android app with EU funding are symptomatic of this.

\section{Experimentality, precarity and debilitation in borderzones}

On 15 March 2018, the European Court of Human Rights (ECtHR) issued its ruling in the case of a Sudanese national who had arrived in Greece in 2009 and who had repeatedly tried to lodge an application for asylum between 2009 and 2012 (ECtHR 2019). In 2012, his application was finally registered at the Regional centre in Attica, but then rejected as manifestly unfounded a year later. The ECtHR found that Greece violated the applicant's right of access to protection under Article 13 of the European Convention on Human Rights and highlighted that 'that the possibility to lodge an asylum application in practice is a prerequisite for the effective protection of those in need of international protection' (European Database of 
Asylum Law 2018). The judgement details the conditions that migrants were subjected to in order to be able to lodge an asylum application, in the period 2009-2012:

only twenty applicants per week had access to the asylum procedure; asylum applicants were not allowed to wait in front of the building of the Attica Aliens Service and were confined to a street nearby; they used to arrive on Wednesday and were queuing for three days in deplorable conditions; during this time, they slept in the street, exposed to difficult weather conditions, without access to toilets, drinking water and food; several time, violent incidents occurred as those who did not queue tried to use violent means to occupy the first twenty places; the police did not intervene to stop these types of incidents....(ECtHR 2019 translation mine).

The Court endorses this description of the situation based on similar information provided by the UNHCR and a report by the Campaign for Access to Asylum. This case reiterates some of the earlier conclusions by the Strasbourg Court in the seminal case M.S.S. $v$ Belgium and Greece that had already found Greece in breach of the Convention given systemic deficiencies in the its asylum system (ECtHR 2011). Yet, rather than reform or overhaul of the system, we can see an orientation towards experimentality developing.

The increased role of EU agencies, of international NGOs and international actors like the UNHCR and IOM means that the governing of borders becomes increasingly shaped by pilot tests, trial and funding applications. Greek borderzones are teeming with 'unmarked' experiments, from floating walls to stop migrants reaching the Greek shores from Turkey to debit cards, and from surveillance devices to creative experiments on refugee integration. All these devices are inserted in reality to recompose social relations between migrants, NGOs, border guards and asylum authorities. A more fluid understanding of experiment is reiterated by humanitarian actors themselves. The UNHCR, for instance, defines experimentation in opposition to planning as an approach to innovation.

Experimentation is a bit like innovation, a word that can mean different things to different people and in the worst case, it is just an empty word without meaningful intent. However, experimenting itself doesn't need to be complicated, in the purest form it is about trying things out in small-scale. We don't need to know the extensive experimentation vocabulary to test our ideas or to experiment (Saarelainen 2017).

A particular type of experiment emerges, which is based on the 'small-scale' injection of devices into reality, for limited periods of time, with the purpose of speculatively making a different future. As Murphy has aptly phrased it, experimentality 'calls social relations into febrile rearrangement, legitimating a continuous refreshing of destruction at a microscale as relations are offered up as decomposable and called to recomposition over and over' (Murphy 2017, 82). While the use of Skype by the Greek Asylum Service did not require additional funding, this rationality becomes more explicit in the creation of the app that 
accompanies its procedures (Asylum Service Application) and which was developed with EU funding. ${ }^{6}$

Let us start by looking at how the obligatory insertion of Skype in the asylum registration process has recomposed these relations between migrants and the state. In the 'User instructions for the asylum claim scheduling service', the Greek Asylum Service presents the service as registration without queuing. The information for English and French speakers dates from 2014 and gives alternative of using an internet café, a computer or a tablet/phone in French (and only a computer, smartphone or tablet in English). The PDF document available online has not been updated so that 'users' are warned to only call on Wednesdays between 11.00-13.00 for English/French and to use the skype ID 'asylum.service' (Greek Asylum Service 2015). At the time of writing, this information sheet had not been amended since 2015, while there have been several versions of the Skype schedule.

The lack of updating is systematic across the Skype procedure and the app. As media theorist Wendy Chun has argued, for digital technologies, 'to be is to be updated' (Chun 2016, 17). Digital technologies require constant updating in order to work. Yet, updating depends on both human labour and material resources. Not only are PDF documents not easily updateable, but contradictory documents co-exist side by side. An updated PDF document has been placed alongside an outdated one on the same page of the Asylum Service (Figure 1). The documents provide different dates and times for Skype pre-registration or various language speakers. Thus, finding the updated PDF has been hardly straightforward - the two are not listed separately, but as part of a long text on the asylum procedure. Moreover, I could compare them on a laptop screen and decide which one was the latest document. Imagine how much more difficult that would be if the documents were to be downloaded on a mobile phone - or impossible, as the case was with the mobile app, where a supplementary app would have been needed to open the PDF file.

\section{What is the procedure}

Access to international protection (asylum) procedure system is free of charge.

You must submit your application in person to one of the Regional Asylum Offices or Asylum Units. You may also submit applications for members of your family, provided that they are also in Greece and that they wish to do so. They will also have to come to the Asylum Service with you. Due the large number of persons who wishes to submit an application you may not be able to actually submit you application if you present yourself to the Asylum Service. Therefore, you might book an appointment for the submission of your application (full registration) via Skype (how to book an appointment via Skype). During your skype call your photograph will be taken and you will be asked to provide some personal information (e.g. name, surname, etc) in order for the Asylum Service to be able to identify you the day you present yourselt to receive your applicant's card or the day of your appointment to submit your application.

In case you cannot communicate with the Asylum Service staff, during the procedure of submitting your application, an interpreter will be present in order to assist you. When submitting your application, you will have to answer to all questions the Asylum Service staff asks you with absolute truthfulness. If you provide false evidence or make false claims, this is going to have a negative effect on the decision of your application.

Figure 1 Greek Asylum Service, Two different hyperlinked Skype appointment documents ${ }^{7}$ 
The lack of updating is one of the first indications of precarity in neoliberalism. While the ECtHR judgements find the asylum system lacking, none of them mentions the restructuring of the Greek state in the midst of the debt crisis. The turn to experimentality needs to be situated against the background of the financial crisis, the Greek debt crisis and the reorganisation of neoliberalism (Mirowski 2013). In Stathis Kouvelakis's $(2018,3)$ diagnosis, 'Greece has served as the laboratory for particularly brutal austerity policies, whose application has been accompanied by an exceptional form of government through which the country is administered by its creditors - the EU and, in a second tier, the International Monetary Fund'. ${ }^{8}$ The emphasis on neoliberal policies and responses to the debt crisis highlight the intensity of precarity in Greece. Moreover, neoliberalism has increasingly normalised precarity understood as a 'structured category of ordering segmented relation of violence and inequality' (Lorey 2015). Experimentality aims to address precarity, not by redressing it, but by recomposing relations of precarity in a different guise. Precarity is decomposed and recomposed rather than reduced or redressed. Skype rearranges relations between asylum applicants and the Greek state, as well as relation between the state and non-state actors.

The Skype schedule works through segmentation as a socio-material practice that divides populations according to a series of explicit and implicit characteristics: nationality, languages spoken and country recognition rates. This segmentation is preceded by an earlier segmentation between Greek islands and mainland, with different practices of asylum registration and access. The Skype pre-registration procedure applies to migrants who are present on the mainland in Greece. The latest Skype schedule lists 15 languages. However, the choice of languages is not explained. For instance, Turkish is missing, while Turkey is listed as the fifth country of origin by total numbers of refugees arriving in Greece (Greek Council for Refugees 2019c). ${ }^{9}$ The schedule for calling the Asylum service is not only coded by hours, weeks and languages but through a complex geographical distribution of zonality. Take, for instance, the schedule for Arabic speakers. Not only are particular hours separated according to particular regions but the time for Arabic speakers is further segmented between Syria Fast Track and other Arabic speakers, following the segmentation of different procedures between mainland/island and before/after the Turkey-EU agreement. ${ }^{10}$ What should take precedence here - is it nationality or is it language? Which language should take precedence when migrants speak more than one language? Moreover, the schedule produces disorientation through the combination of separation of language and nationality - Arabic and Syrian - as well as ambiguity about the status of dual-language speakers. ${ }^{11}$ The Mobile Info Team also points out that Skype access will likely be policed according the a determination of what counts as an applicant's mother tongue: 'You most likely will only get an appointment on the English-language Skype line if English is your mother tongue, so it is not enough to speak very good English' (Mobile Info Team n.d.). 
Skype Program after 28/01/2019

\begin{tabular}{|c|c|c|c|c|c|}
\hline Hours & Monday & Tuesday & Wednesday & Thursday & Friday \\
\hline 08:00 - 09:00 & $\begin{array}{l}\text { Arabic } \\
\text { Athens }\end{array}$ & \begin{tabular}{|l|} 
Albanian \\
$8: 00-8: 30$ \\
Rest of Greece \\
(without Ioannina) \\
8:30 - 9:00 \\
Ioannina, Leros
\end{tabular} & $\begin{array}{l}\text { Albanian } \\
\text { Rest of Greece }\end{array}$ & $\begin{array}{l}\text { Albanian } \\
\text { Thessaloniki }\end{array}$ & $\begin{array}{l}\text { Albanian } \\
\text { Athens }\end{array}$ \\
\hline $09: 00-10: 00$ & $\begin{array}{l}\text { Arabic } \\
\text { Athens }\end{array}$ & $\begin{array}{l}\text { Kurmandji } \\
\text { All of Greece }\end{array}$ & $\begin{array}{l}\text { English-French } \\
\text { All of Greece }\end{array}$ & $\begin{array}{l}\text { Pashto } \\
\text { All of Greece }\end{array}$ & $\begin{array}{l}\text { Pashto } \\
\text { All of Greece }\end{array}$ \\
\hline $10: 00-11: 00$ & $\begin{array}{l}\text { Dari } \\
\text { All of Greece }\end{array}$ & $\begin{array}{l}\text { Dari } \\
\text { All of Greece }\end{array}$ & $\begin{array}{l}\text { Farsi } \\
\text { All of Greece }\end{array}$ & $\begin{array}{l}\text { Dari } \\
\text { Athens }\end{array}$ & $\begin{array}{l}\text { Georgian } \\
\text { Athens }\end{array}$ \\
\hline $11: 00-12: 00$ & $\begin{array}{l}\text { Sorani } \\
\text { All of Greece }\end{array}$ & $\begin{array}{l}\text { Arabic } \\
\text { Thessaloniki, } \\
\text { Rhodes, Leros }\end{array}$ & $\begin{array}{l}11: 00 \text { - } 11: 30 \\
\text { Syria Fast Track } \\
11: 30 \text { - 12:00 } \\
\text { Arabic - Athens }\end{array}$ & $\begin{array}{l}\text { Arabic } \\
\text { All of Greece } \\
\text { (without Thess., } \\
\text { Rhodes, Leros) }\end{array}$ & $\begin{array}{l}\text { Arabic } \\
\text { Athens }\end{array}$ \\
\hline $12: 00-13: 00$ & $\begin{array}{l}\text { Urdu - Punjabi } \\
12: 00-12: 30 \\
\text { Rest of Greece } \\
\text { (without Ioannina) } \\
12: 30 \text { - 13:00 } \\
\text { Ioannina }\end{array}$ & $\begin{array}{l}\text { Urdu - Punjabi } \\
\text { Athens }\end{array}$ & $\begin{array}{l}\text { Sorani } \\
\text { All of Greece }\end{array}$ & $\begin{array}{l}\text { Hindi } \\
\text { 12:00-12:30 } \\
\text { Thessaloniki } \\
\text { 12:30-13:00 } \\
\text { Athens }\end{array}$ & $\begin{array}{l}\text { Russian - } \\
\text { Ukranian } \\
\text { All of Greece }\end{array}$ \\
\hline $13: 00-14: 00$ & $\begin{array}{l}\text { Georgian } \\
\text { Rest of Greece }\end{array}$ & $\begin{array}{l}\text { Georgian } \\
\text { Rest of Greece }\end{array}$ & $\begin{array}{l}\text { Chinese } \\
\text { All of Greece }\end{array}$ & $\begin{array}{l}\text { Bengali } \\
\text { Athens }\end{array}$ & $\begin{array}{l}\text { Bengali } \\
\text { Rest of Greece }\end{array}$ \\
\hline
\end{tabular}

Figure 2 Schedule for Skype calls (as of 28 January 2019) ${ }^{12}$

The Skype experiment rearranges relations between migrants and the state by reconfiguring precarity rather than reducing either the precarity of material resources or the precarity of migrant lives. In so doing, experimentality becomes effectively a practice of debilitation. As Jasbir Puar has indicated, technology 'acts both as a machine of debility and capacity and as portals of affective openings and closures' (Puar 2017, 27). Through the insertion of Skype in the asylum process, refugees continually experience debilitation through the technology that doesn't work, closure through limited access and disorientation through contradictory and outdated information.

In a 2019 report submitted by a coalition of NGOs to the UN Committee on Torture, the Skype procedure has been highlighted again as a problem. Although extended to more languages, the Skype procedure inevitably enacts exclusions of those whose native language does not count among those selected for the Skype procedure. The report also points out that

it is not unusual for asylum seekers to call the line every week for months in frustration and never be able to get through. As a result, asylum seekers will often have their police notes expire before they are able to register themselves through Skype, lose their access to humanitarian assistance and risk detention' (Lucas, Ramsay, and Keen 2019). 
A UNHCR set of recommendations on Greece's implementation of the ECtHR judgement in M.S.S. $v$ Belgium and Greece also highlights the long delays due to the limited capacity of the Skype system, personnel and interpreters:

Delays in interview scheduling times all over Greece are indicative of the extent of the current challenges. In Attica, the Fast-track Syria Unit applicants receive interview appointments for 2021, while in Thessaloniki interview dates are currently given for 2024 for applicants from Turkey, Iran and Afghanistan, and for late 2023 for Iraq and for African countries' (UNHCR 2019, 2).

In 2018, the Greek Asylum Service, in collaboration with academics from the Harokopio University of Athens, and with funding from the European Union, developed a mobile application providing information for migrants on registering their asylum claims and using Skype for pre-registration. The Asylum Registration Service app can be downloaded from Google Play Store and is thus accessible only for phones running Android. ${ }^{13}$ I downloaded the app in December 2019 and used the 'walkthrough' method to understand how the app renders relations between asylum applicants, state and non-state institutions. ${ }^{14}$ What struck me first about the app was its dense textuality. The first interface of images gives way to dense textual information that fills up the screen of a small Android phone. Each block of text takes the user to the website of the Greek Asylum Service and requires watching high data usage audio-visual material or downloading large PDF files. The document for Skype schedule was $1.34 \mathrm{MB}$ and could not be opened on my Android phone, as a supplementary app was required to read PDF files. The app also includes Notifications, which are listed in reverse chronological order. Notifications are not deleted, so you need to scroll down through all notifications since 2016 to reach the present. Notifications can contain important information about policy changes and timeframes for applications, but they are almost impossible to access from the app.

At first sight, we could simply say that these are problems of app design. Yet, experimentality sheds light on a different dimension of injecting mundane digital devices into the reality of borderzones. Similar issues with outdated information and lack of updating also plague the app. After managing to open the Skype scheduling file by sending it to my email address and opening it on a computer, I found out that the information had not been updated since 2017. The 2017 schedule was organised by language, the 2019 schedule is organised by hourly slots. Not only would a speaker of English or Arabic call at different hours, but they would also not know that the language they choose must be their native language.

Much of the criticism of the use of Skype technologies has focused on the exclusion of particular categories of migrants and the technology's inefficiency. Yet, experimentality also orients us to how precarity is recomposed in relations between state and refugees. As this section has shown, experimentality does not redress precarity and does not end either the endemic violence that migrants experience or the lack of resources. Digital technologies do not require less, but often more labour, as they are constantly in need to be updated to stay 
the same. Skype appears to efface this need for labour, as it has been bought by Microsoft, so the labour of producing and updating the software is not visible. In the next section, I show another recomposition of relations through experimentality. Mundane digital devices insert refugees within wider circuits of platform capitalism so that a different mode of debilitation is produced through experimentality.

\section{Experimental users, surplus data, extraction}

In this section, I attend to the recomposition of relations between refugees, state and the 'invisible' providers of digital devices, such as Microsoft (for Skype) or Google (for downloading the app on Google Play Store). Many of the technologies that are deployed by NGOs and state actors in experimental practices are produced elsewhere, often by corporate actors who remain entangled in the experiments through their expertise and ownership of these technologies. Borderzone experimentality is thus also entangled with the extractive operations of 'platform capitalism' (Srnicek 2017). Digital platforms such as Facebook, Microsoft, Amazon, Google or Airbnb do not only shape relations between participants online, but they transform value and markets. As Nick Srnicek explains, given the drive to accumulate data, the more certain platforms are used, the more valuable these platforms become (2017). Digital platforms depend upon the extraction, processing and analysis of data, which has become a new source of profit generation and capital accumulation. Experimentality is therefore intrinsic to the extension of digital platforms, which incorporate more and more spheres of private life by rendering them into computable data.

To understand the political effects of digital devices like Skype, Whatsapp and other mobile apps, we need to understand them as data-extractive devices. Digital platforms depend upon the extraction, processing and analysis of data, which has become a new source of profit generation and capital accumulation. I call this data 'surplus data', as it is not just the data that is collected by state and non-state actors through databases, statistics about migration routes, or projections of flows, but data that produces surplus value. While I do not engage with the wide-ranging discussion about Marx's theory of labour value, I draw here on the distinction between use value and surplus value (Marx 1986 [1867]). Surplus value is created through the production of commodities that can enter into capitalist circuits of exchange. Surplus data is data that garners value in exchange. ${ }^{15}$ Using the terminology of use data and surplus data rather than the more common one of captured data and exhaust or 'leak' data helps render the extractive character of various forms of data.

The focus on the collection and processing of digital data by state and non-state actors has given rise to concerns about surveillance or dataveillance of mobile populations in borderzones (see e.g. Broeders and Dijstelbloem 2015; Topak et al. 2015; Scheel, Ruppert, and Ustek-Spilda 2019) and migrant profiling through 'non-representational categories rather than actual real-life social groups' (Leese 2014, 504). Surplus data refers to data that is not immediately used by states for border governance, but that remains 'invisible' while indispensable to platform capitalism. A different form of surveillance is at work here - one 
which does not necessarily take hold of migrants' bodies - but aims at grasping the whole population. In platform capitalism, experiments with data are continually conducted on digital platforms by corporate actors. Tech companies run in vivo A/B testing to decide what data associations make a difference ( $\mathrm{Ng}$ 2017). If these experiments take place elsewhere, migrants and refugees enter these experiments without protocol. The experiments running on platforms remain invisible to them, and the protocols that might be in place in the private companies do not extend to them.

Data protection and privacy offer a limited prism through which to understand the extraction of surplus data in these wider digital platforms. Even as many humanitarian actors have started to address concerns about data protection and privacy, experiments without protocol go beyond data protection and privacy regulations. Not only are migrants and refugees often excluded from the remit of data protection under the mantra of national security or public security, but the state collection of data can even dispense with privacy and data protection. ${ }^{16}$ For the experimental user, 'offering up one's privacy [... as] the very currency of proven competency and proficiency' (Puar 2017, 32) is not even a choice. The Greek Asylum Service mentions nothing about privacy and the protection of migrant data in the use of the Skype procedure. The Asylum Information Application has no data protection or privacy policy. In a paper presented at the Migration Conference, the app developers, together with a representative of the Greek Asylum Service, note that further developments of the app would include 'the gathering of usage statistics and their consequent analysis, in order to derive useful information regarding its acceptance and diffusion among the asylum seekers and useful information regarding the asylum seekers themselves' (Makris et al. 2017). 'Information regarding the asylum seekers themselves' refers not only to personal data but can have consequences for both rights and the safety of asylum seekers.

The question of surveillance through data extraction by both state and non-state actors has been increasingly discussed by international actors such as Privacy International and the International Committee of the Red Cross (ICRC). While much of this discussion has focused on the relation between humanitarian actors and states, a recent report by the ICRC and Privacy International raised the question of 'digital intermediaries', which different organisations mobilise to produce and deploy digital devices (International Committee of the Red Cross (ICRC) and Privacy International 2018). The report also notes that 'Until recently, Android operating systems had no inbuilt way of allowing users to specify app permissions' (International Committee of the Red Cross (ICRC) and Privacy International 2018, 103). Anyone having an old phone - as the phone I had used to download the Asylum Information Application - had no option to specify permissions, such as the collection of location data.

These digital intermediaries can be visible - for instance, as the explicit providers of the technology - but they are often invisible, a multitude of actants in the disperse networks of platform capitalism. These can be both state and private actors. After the Snowden disclosures in 2013, The Guardian reported that Microsoft had been turning over audio and visual to the NSA, including Skype data (Greenwald et al. 2013). Microsoft had acquired Skype just a few years earlier, in 2011, and had tripled the amount of Skype video calls it handed 
over to the NSA. While Skype was then cleared of unlawful behaviour over its collaboration with the NSA in a case investigated by Luxembourg's Data Protection Commissioner, these other flows of data are not collateral but intrinsic to experimentality in borderzones.

Alongside the data that migrants have to give in the process of registration and identification, they also produce 'surplus data' as their data enters capitalist circuits of exchange through the digital platforms that Microsoft owns. The use of Skype depends on agreeing to Microsoft's Privacy policy, which allow Microsoft to collect a wide range of data from users:

Microsoft collects data from you, through our interactions with you and through our products. You provide some of this data directly, and we get some of it by collecting data about your interactions, use, and experiences with our products. The data we collect depends on the context of your interactions with Microsoft and the choices you make, including your privacy settings and the products and features you use. We also obtain data about you from third parties (Microsoft 2019).

Microsoft does only collect data, but it shares this data widely. The exact extent of data collection and sharing remains ambiguous in their Privacy policy:

We share your personal data with your consent or to complete any transaction or provide any product you have requested or authorized. We also share data with Microsoft-controlled affiliates and subsidiaries; with vendors working on our behalf; when required by law or to respond to legal process; to protect our customers; to protect lives; to maintain the security of our products; and to protect the rights and property of Microsoft and its customers (Microsoft 2019).

What is striking in this formulation of privacy and data protection is its ambiguity about what exactly is collected and what exactly is shared. Ultimately, these policies enable Microsoft's data-extractive operations. The Privacy policy enjoins the user to read further and look into the forms of data that are collected and to use technological proficiency to change standard settings to increase privacy. Experimentality in borderzones help us shed light on how migrants are unwillingly enrolled in these distributed experiments. They are both excluded from protocols that might be at work elsewhere, while being implicitly enjoined to experiment if they want to understand the extent and forms of data collection and sharing that Microsoft engages in.

Enrolling migrants as experimental users of technology opens them to 'surplus' data extraction in an indeterminate future of speculation. The contours and trajectories of 'surplus' data remain uncertain, shrouded in ambiguity and indeterminacy. While the trajectories of digital data are increasingly difficult to follow, given the number of states and NGOs collecting, processing and analysing data from and about migrants, the trajectories of 
surplus data are even more complex, as they are entangled in the circuits and infrastructures of platform capitalism.

Migrants and refugees cannot refuse the invisible labour of producing data surplus for Microsoft, Google and other tech companies. As recent research on tracking users on mobile platforms has shown, the business model of platforms relies on the embedding 'third-party' trackers into 'first-party' mobile applications, so that over $90 \%$ of all the apps were found to contain a tracker by a company based in the United States (Binns et al. 2018, 6). In the realm of platform capitalism, both labour and experiments with surplus data remain invisible, their protocols unwritten or unseen. In the case of the contentious development of iBorderCTRL, the technology supposedly using Al to detect deception at borders, MEP Patrick Breyer could demand the ethical assessments of the trials (Stolton 2020). This would be impossible for the experiments without protocol that inject mundane digital devices in borderzones.

Enrolling migrants in digital platforms not only extracts that labour and data, but also deprives them of rights. In Greece, neither the state nor other actors such as UNHCR use this data for the purposes of individual surveillance (see Aradau and Tazzioli 2020). Yet, a recent report by Gesellschaft für Freiheitsrechte has shown a very different situation in Germany, where refugees who cannot show a passport or other identification document are obliged to hand over their mobile phone where data is algorithmically processed to establish their identity. This includes names used to login to apps, location data from photos and potentially apps, as well as browser domains (Gesellschaft für Freiheitsrechte 2020). The 'surplus data' that tech companies extract is turned into a tool of surveillance by the state through the use of Al. Not only are these processes plagued by error, but they alert us to the extensive deprivation of rights. Moreover, the proliferation and dispersal of these experiments with data-extractive devices renders these processes increasingly invisible and difficult to understand.

\section{Conclusion}

Borderzones have become replete with digital devices that aim to render mobility governable. While much of the analytical attention has focused on high-tech devices such as Al-powered lie detectors, drones, thermal vision cameras or interoperable databases, I have proposed to attend to more mundane digital devices such as Skype software for VolP or mobile applications. After the fire that destroyed the Moria camp in Lesvos, the Ministry of Migration and Asylum set up a Viber channel for refugees. The injection of small tech devices into borderzones has often been rendered as part of the drive for 'innovation' for both humanitarian actors and the security industry. Yet, experimentality is not limited to NGOs and private actors, but has become a mode of statecraft as well. Drawing on research in anthropology and STS, I have proposed to approach experimentality as a mode of governing in borderzones, which recomposes social relations in a 'febrile rearrangement' (Murphy 2017, 82) towards speculative futures, through the injection of devices into the real world. 
Experimentality deploys experiments in the artificial spaces of the laboratory, the clinic but also in the real world. In this paper, I have focused on experiments without protocol, as these can have even more insidious effects for the lives of migrants and refugees.

Experimentality does not only help shed light on the heterogeneity and variability of governmentality in borderzones, but it also makes visible these real - and debilitating political effects. Critical work on border studies, particularly on the Greek borderzones, has emphasised the violence of pushbacks, non-rescue, refoulement and living conditions in the cramped spaces of detention camps. The introduction of the Skype procedure and the creation of an information app for asylum applicants in Greece reproduce narratives of connectivity, accessibility and information. Yet, I have argued that experimentality in borderzones rearranges relations of precarity and extraction, entailing debilitation and deprivation. Digital devices need labour and resources for updating and connecting. This need for continuous updating produces complex temporal entanglements of obsolescence: information that is obsolete, information that is about to become obsolete and information whose obsolescence is uncertain. I have shown that experimentality does not tackle precarity, but it recomposes relations between refugees and the state as relations of precarity. Experimentality also exposes migrants and refugees to further political deprivation, as it enrols them into extractive relations on digital platforms.

Experimentality helps nuance analyses of border governmentality and contributes to an analysis of heterogeneous rationalities of governing. If neoliberalism produces precarity, experimentality does not reduce relations of precarity but rearranges them. If neoliberalism aims to foster entrepreneurial subjects, experimental subjects are unwillingly drawn into experiments without protocol. Finally, experimentality also helps us understand borderzones as not only teeming with technologies and devices, but also as sites of value creation through 'surplus data'.

The analysis developed here evokes two aspects of experimentality that need further critical attention. Firstly, the focus here was on experiments without protocol through mundane digital devices. As the example of Germany indicates, other experiments are underway, where states can access surplus data to surveil refugees. How can we account for these differences in experimentality? What kind of geopolitical zoning of experiments is at stake here? Secondly, I started with a critical intervention by Rania Ali. Yet, her critique of the failure of Skype, as well as those of other actors are continuously folded back into further pilots, trials, innovation and experiments. What kinds of critical interventions do we need develop that might thwart experimental interventions and reclaim experiments as potentially creative rather than speculative making of different futures?

\section{Notes}


${ }^{1}$ Greece has different procedures of access to asylum depending on whether migrants reach the islands in the Aegean or the Greek mainland. Since the signature of the EU-Turkey agreement, migrants on the islands arriving via Turkey can only enter the normal asylum procedure if they are classified as 'vulnerable' (Greek Council for Refugees 2019a). Otherwise, they need to follow a fast-track border procedure. According to the fast-track border procedure, interviews are conducted by the European Asylum Support Office (EASO) in order to assess the vulnerability of applicants and make a decision on whether Turkey is a 'safe third country' for them (European Council 2016).

${ }^{2}$ As Vicki Squire has argued, borderzones are sites of both control and struggle (Squire 2011).

${ }^{3}$ On the distinction between 'low-tech' and 'high-tech' security, see (Bonelli and Ragazzi 2014).

4 There are many debates about the political uses of categories of 'migrants', 'refugees' and 'asylum seekers'. To avoid the reification of categories and also to acknowledge their fluid status in practice, I use them interchangeably here.

${ }^{5}$ Rhys Machold has criticised the 'laboratory thesis' in security studies for not being 'groundbreaking and analytically robust' (Machold 2018, 90). Rather than discarding the terminology of 'laboratory', he proposes to reinvigorate it through engagement with ANT/STS literature, as critical borders scholars have also started to do.

https://play.google.com/store/apps/details?id=com.ionicframework.asylumapp646672\&hl=en\&showAllRevie ws=true.

7 http://asylo.gov.gr/en/?page id=72.

8 Interestingly, Kouvelakis uses 'laboratory' metaphorically.

${ }^{9}$ Turkish asylum seekers do not need to use the Skype procedure, but need to give their phone number to the Regional Asylum Office Attica. The No End in Sight report notes that interviews with Turkish asylum seekers are scheduled for 2025 (Lucas, Ramsay, and Keen 2019).

10 The Syria Fast Track procedure is a special procedure introduced since 2014 for Syrian nationals and stateless persons who entered Greece before the Turkey-EU agreement in 2016 or entered via the land borders (Greek Council for Refugees 2019b).

${ }^{11}$ On borders as unpredictable regimes that create high degrees of uncertainty for migrants, see Stephan Scheel (2019 Chapter 4).

12 http://asylo.gov.gr/en/wp-content/uploads/2019/02/Skype-programme-28-1-19_compressed.pdf

13 https://www.inhereproject.eu/universities/harokopio-university-of-athens-el-study-in-greece-ngo

${ }^{14}$ The 'walkthrough' method involves engaging with the app, downloading it, working through the menu and tapping buttons as a user might do (Light, Burgess, and Duguay 2018).

15 'Surplus data' also draws attention to the invisible labour that is needed to produce this data. While Greek authorities process the content of the Skype data, what is key here is the simultaneous production of data for exchange which produces surplus value ('surplus data').

${ }^{16}$ These are some of the exceptions listed in the EU's General Data Protection Regulation (GDPR, Article 23 'Restrictions'). In the UK, the Data Protection Act 2018 contains an 'immigration exemption', which was unsuccessfully challenged in court by campaigners.

\section{Acknowledgements}

I would like to thank the special issue editors, Matthias Leese, Simon Noori and Stephan Scheel for the invitation to contribute to the special issue and their thoughtful comments on earlier drafts. I am grateful to the three anonymous reviewers and to the editor, Nancy Hiemstra, for generous suggestions and pushing me to clarify conceptual distinctions and the analytical language of experimentality. Keina Espiñeira González, Alvina Hoffmann and Sarah Perret on the SECURITY FLOWS project have offered invaluable critiques and reading suggestions. I would like to acknowledge Sarah Perret's coinage of 'experiment without protocol', which I have adopted in this final version. 


\section{Funding}

This work was supported by funding from the European Research Council (ERC) under the European Union's Horizon 2020 research and innovation programme (SECURITY FLOWS, grant agreement No 819213).

\section{ORCID}

Claudia Aradau http://orcid.org/0000-0003-2010-9006

\section{References}

Ali, R. 2016a. Help the refugees stuck in Greece. www.change.org. Accessed 2 February 2019. https://www.change.org/p/skype-is-no-solution-we-need-face-to-faceservices-for-refugees-in-greece-livesonhold/u/17260715.

---. 2016b. Skype is no solution - we need face-to-face services for refugees in Greece. www.change.org. Accessed 2 February 2019. https://www.change.org/p/skype-isno-solution-we-need-face-to-face-services-for-refugees-in-greece-livesonhold.

Amnesty International. 2019. Automated technologies and the future of Fortress Europe. Accessed 9 January 2020.

https://www.amnesty.org/en/latest/news/2019/03/automated-technologies-andthe-future-of-fortress-europe/.

Aradau, C., and M. Tazzioli. 2020. Biopolitics Multiple: Migration, Extraction, Subtraction. Millennium 48 (2): 198-220. https://doi.org/10.1177/0305829819889139. https://journals.sagepub.com/doi/abs/10.1177/0305829819889139.

Bialasiewicz, L. 2012. Off-shoring and Out-sourcing the Borders of EUrope: Libya and EU Border Work in the Mediterranean. Geopolitics 17 (4): 843-866.

https://doi.org/10.1080/14650045.2012.660579. https://doi.org/10.1080/14650045.2012.660579.

Binns, R., et al. 2018. Third Party Tracking in the Mobile Ecosystem. WebSci '18 Proceedings of the 10th ACM Conference on Web Science, Amsterdam, Netherlands.

Bonelli, L., and F. Ragazzi. 2014. Low-tech security: Files, notes, and memos as technologies of anticipation. Security Dialogue 45 (5): 476-493.

Bourne, M., H. Johnson, and D. Lisle. 2015. Laboratizing the border: The production, translation and anticipation of security technologies. Security Dialogue 46 (4): 307325. https://doi.org/10.1177/0967010615578399. http://journals.sagepub.com/doi/abs/10.1177/0967010615578399.

Broeders, D., and H. Dijstelbloem. 2015. The Datafication of Mobility and Migration Management. In Digitizing Identities: Doing Identity in a Networked World, edited by I. van der Ploeg and J. Pridmore, 242-260. New York: Routledge.

Brown, W. 2015. Undoing the Demos: Neoliberalism's stealth revolution. New York: Zone Books. 
Cabot, H. 2014. On the Doorstep of Europe: Asylum and citizenship in Greece. Philadelphia: University of Pennsylvania Press.

Campesi, G. 2018. Seeking Asylum in Times of Crisis: Reception, Confinement, and Detention at Europe's Southern Border. Refugee Survey Quarterly 37 (1): 44-70. https://doi.org/10.1093/rsq/hdx016. https://doi.org/10.1093/rsq/hdx016.

Chun, W. H. K. 2016. Updating to Remain the Same: Habitual New Media. Cambridge, Mass.: MIT Press.

De Genova, N. 2017. The border of 'Europe' and the European question. In The Borders of 'Europe': Autonomy of migration, tactics of bordering, edited by N. De Genova, 1-35. Durham: Duke University Press.

Digidiki, V., and J. Bhabha. 2020. Greece's proposed 'floating wall' shows the failure of EU migration policies. The Guardian. Accessed 6 June 2020.

https://www.theguardian.com/commentisfree/2020/feb/07/greece-floating-walleu-refugees-migrant-policy.

ECtHR. 2011. Case of M.S.S. v. Belgium and Greece. Grand Chamber. Accessed 9 July 2020. http://hudoc.echr.coe.int/fre?i=001-103050.

---. 2019. Affaire A.E.A. c. Grèce (no 39034/12). ECHR. Accessed 4 December 2019. http://hudoc.echr.coe.int/app/conversion/docx/pdf?library=ECHR\&id=001181818\&filename=CEDH.pdf.

Eule, T. G., D. Loher, and A. Wyss. 2018. Contested control at the margins of the state. Journal of Ethnic and Migration Studies 44 (16): 2717-2729.

https://doi.org/10.1080/1369183X.2017.1401511. https://doi.org/10.1080/1369183X.2017.1401511.

Euro-Mediterranean Human Rights Monitor. 2020. EU Should Cancel €59M Contract with Israeli Companies for Drones to Surveille Migrants. Accessed 2020. https://euromedmonitor.org/en/article/3529/EU-Should-Cancel-\%E2\%82\%AC59MContract-with-Israeli-Companies-for-Drones-to-Surveille-Migrants.

European Council. 2016. EU-Turkey statement, 18 March 2016. Press Release. Accessed 16 December 2019. https://www.consilium.europa.eu/en/press/pressreleases/2016/03/18/eu-turkey-statement/.

European Database of Asylum Law. 2018. A.E.A. v Greece (application no. 39034/12) [violation of Article 13 ECHR read in conjunction with Article 3 ECHR]. EDAL. Accessed 12 April 2019. https://www.asylumlawdatabase.eu/en/content/aea-vgreece-application-no-3903412-violation-article-13-echr-read-conjunction-article-3.

Gallagher, R., and L. Jona. 2019. We tested Europe's new lie detector for traveller - and immediately triggered a false positive The Intercept. Accessed 3 July 2020. https://theintercept.com/2019/07/26/europe-border-control-ai-lie-detector/.

Gesellschaft für Freiheitsrechte. 2020. Invading Refugees' Phone: Digital forms of migration control. Accessed 19 July 2020. https://freiheitsrechte.org/home/wpcontent/uploads/2020/02/Study Invading-Refugees-Phones Digital-Forms-ofMigration-Control.pdf. 
Greek Asylum Service. 2015. User instructions for the asylum claim scheduling service.

Accessed 10 March 2019. http://asylo.gov.gr/en/wp-

content/uploads/2015/01/\%CE\%9F\%CE\%B4\%CE\%B7\%CE\%B3\%CE\%AF\%CE\%B5\%CF\%

82-\%CE\%A7\%CF\%81\%CE\%AE\%CF\%83\%CE\%B7\%CF\%82-

\%CE\%9A\%CE\%BF\%CE\%B9\%CE\%BD\%CE\%BF\%CF\%8D ENandFR final.pdf.

Greek Council for Refugees. 2019a. Country Report: Greece. Asylum Information Database.

Accessed 8 July 2020. http://www.asylumineurope.org/reports/country/greece.

---. 2019b. Differential Treatment of Specific Nationalities in the Procedure. AIDA/ECRE.

Accessed 30 September 2020.

https://www.asylumineurope.org/reports/country/greece/asylum-

procedure/differential-treatment-specific-nationalities-procedure\# ftnref1.

---. 2019c. Overview of statistical practice. Accessed 18 April 2019.

https://www.asylumineurope.org/reports/country/greece/statistics.

Greenwald, G., et al. 2013. Microsoft handed the NSA access to encrypted messages. The Guardian. https://www.theguardian.com/world/2013/jul/11/microsoft-nsacollaboration-user-data.

Hacking, I. 1983. Representing and Intervening: Introductory topics in the philosophy of natural science. Cambridge: Cambridge University Press.

International Committee of the Red Cross (ICRC), and Privacy International. 2018. The Humanitarian Metadata Problem: "Doing no harm" in the digital era.

Jacobsen, K. L. 2015a. Experimentation in humanitarian locations: UNHCR and biometric registration of Afghan refugees. Security Dialogue 46 (2): 144-164.

https://doi.org/10.1177/0967010614552545.

http://journals.sagepub.com/doi/abs/10.1177/0967010614552545.

Jacobsen, K. L. 2015b. The Politics of Humanitarian Technology: Good intentions, unintended consequences and insecurity. London: Routledge.

Kouvelakis, S. 2018. Borderland. Greece and the EU's southern question. New Left Review March/April: 5-33.

Leese, M. 2014. The new profiling: Algorithms, black boxes, and the failure of antidiscriminatory safeguards in the European Union. Security Dialogue 45 (5): 494-511. https://doi.org/10.1177/0967010614544204. http://journals.sagepub.com/doi/abs/10.1177/0967010614544204.

Light, B., J. Burgess, and S. Duguay. 2018. The walkthrough method: An approach to the study of apps. New Media \& Society 20 (3): 881-900.

https://doi.org/10.1177/1461444816675438. http://journals.sagepub.com/doi/abs/10.1177/1461444816675438.

Lorey, I. 2015. State of Insecurity: Government of the Precarious. London: Verso.

Lucas, A., P. Ramsay, and L. Keen. 2019. No End in Sight. The mistreatment of asylum seekers in Greece. Greek Helsinki Monitor, Refugee Rights Europe et al.

Machold, R. 2018. Reconsidering the laboratory thesis: Palestine/Israel and the geopolitics of representation. Political Geography 65: 88-97. 
Makris, A., et al. 2017. Mobile Application for Asylum Seekers. The Migration Conference.

Marres, N., and D. Stark. 2020. Put to the test: For a new sociology of testing. The British Journal of Sociology 71 (3): 423-443. https://doi.org/10.1111/1468-4446.12746. https://onlinelibrary.wiley.com/doi/abs/10.1111/1468-4446.12746.

Marx, K. 1986 [1867]. Capital. Volume One. London: Lawrence and Wishart.

Microsoft. 2019. Microsoft Privacy Policy. Accessed 17 April 2019. https://privacy.microsoft.com/en-US/privacystatement.

Mirowski, P. 2013. Never let a serious crisis go to waste: How neoliberalism survived the financial meltdown. London: Verso.

Mobile Info Team. n.d. How to book an appointment to apply for Asylum through Skype. Accessed 6 January 2020. https://www. mobileinfoteam.org/skype.

Murphy, M. 2017. The Economization of Life. Durham, NC: Duke University Press.

$\mathrm{Ng}, \mathrm{A}$. 2017. The State of Artificial Intelligence. MIT Technology Review. Accessed 8 January 2020. https://www.youtube.com/watch?v=NKpuX yzdYs.

Nguyen, V.-K. 2009. Government-by-exception: Enrolment and experimentality in mass HIV treatment programmes in Africa. Social Theory \& Health 7 (3): 196-217.

Petryna, A. 2009. When Experiments Travel: Clinical trials and the global search for human subjects. Princeton, NJ: Princeton University Press.

Puar, J. K. 2017. The Right to Maim: Debility, capacity, disability. Durham, NC: Duke University Press.

Rabinow, P. 2003. Anthropos Today. Reflections on Modern Equipment. Princeton: Princeton University Press.

Rozakou, K. 2017. Nonrecording the "European refugee crisis" in Greece: Navigating through irregular bureaucracy. Focaal 2017 (77): 36-49.

Saarelainen, E. 2017. Why there's no innovation without experimentation. UNHCR Innovation Service. Accessed 2 April 2019. https://www.unhcr.org/innovation/whytheres-no-innovation-without-experimentation/.

Sargent, R. M. 2004. Robert Boyle and the masculine methods of science. Philosophy of Science 71 (5): 857-867.

Scheel, S. 2019. Autonomy of Migration?: Appropriating mobility within biometric border regimes. London: Routledge.

Scheel, S., E. Ruppert, and F. Ustek-Spilda. 2019. Enacting migration through data practices. Environment and Planning D: Society and Space 37 (4): 579-588. https://doi.org/10.1177/0263775819865791. https://journals.sagepub.com/doi/abs/10.1177/0263775819865791.

Sciortino, G. 2004. Between phantoms and necessary evils. Some critical points in the study of irregular migrations to Western Europe. IMIS-Beiträge 24: 17-43.

Shapin, S., and S. Schaffer. 1985. Leviathan and the Air-Pump: Hobbes, Boyle, and the experimental life. Princeton, NJ: Princeton University Press.

Squire, V., ed. 2011. The Contested Politics of Mobility: Borderzones and Irregularity. Abingdon: Routledge. 
Srnicek, N. 2017. Platform Capitalism. Cambrige: Polity.

Statewatch, and PICUM. 2019. Data Protection, Immigration Enforcement and Fundamental Rights: What the EU's Regulations on Interoperability Mean for People with Irregular Status. Accessed 8 January 2020. https://picum.org/wpcontent/uploads/2019/11/Data-Protection-Immigration-Enforcement-andFundamental-Rights-Full-Report-EN.pdf.

Stolton, S. 2020. MEP: Public has a 'right to know' about Commission's lie detector tech. Euractiv. Last Modified 6 April 2020. Accessed 18 October 2020. https://www.euractiv.com/section/digital/news/mep-public-has-a-right-to-knowabout-commissions-lie-detector-tech/.

Tazzioli, M. 2019. Refugees' subjectivities, debit cards and data circuits. Financialhumanitarianism in the Greek migration laboratory. International Political Sociology. https://doi.org/https://doi.org/10.1093/ips/olz014.

Terre des hommes. n.d. FabLab: An innovation space to reach vulnerable youth. Accessed 18 June 2020. https://www.tdh.ch/en/projects/fablab-innovation-space-reachvulnerable-youth.

Topak, Ö. E., et al. 2015. From Smart Borders to Perimeter Security: The Expansion of Digital Surveillance at the Canadian Borders. Geopolitics 20 (4): 880-899.

https://doi.org/10.1080/14650045.2015.1085024. https://doi.org/10.1080/14650045.2015.1085024.

Towghi, F., and K. Vora. 2014. Bodies, Markets, and the Experimental in South Asia. Ethnos 79 (1): 1-18. https://doi.org/10.1080/00141844.2013.810660. https://doi.org/10.1080/00141844.2013.810660.

UNHCR. 2019. Communication from the United Nations High Commissioner for Refugees (UNHCR) (15/05/2019) in the M.S.S. and Rahimi groups v. Greece (Applications No. 30696/09, 8687/08). Accessed 3 July 2020. https://www.refworld.org/docid/5cffceb04.html.

Walters, W. 2015. Reflections on Migration and Governmentality. movements. Journal für kritische Migrations-und Grenzregimeforschung 1 (1). 